\title{
STUDIES ON THE IMMUNITY BY BCG IN MURINE LEPROSY
}

\author{
Shinji NISHIMURA, Michiyuki KONO* and Masamichi KODAMA \\ (Research Institute for Microbial Diseases, Osaka University) \\ (Dept. of Dermatology, Osaka University Medical School)
}

\author{
Ken YANAGISAWA
}

(National Institute of Health, Tokyo)

\author{
Taiji NOJIMA, Mutsuo MORIYA, Takeyo TAKAHASHI \\ and Shinnosuke OSHIMA \\ (National Leprosarium, Oshima Seishoen)
}

\author{
Masayasu ITO and Masakazu SUZUKI \\ (National Leprosarium, Nagashima Aiseien)
}

From January to September 1955, experiments were carried out to examine the possibility of preventing leprosy by means of BCG injection and murine leprosy was employed for a mean of this purpose.

The experiments were carried our in 3 series, namely, 1) prophylaxis, 2) inhibition of the onset and 3) therapy. And 140 rats were used in total.

I. Experiment of Prophylaxis

Experimental method:

Experimental animal: Young female rats, $70 \mathrm{~g} \pm 10 \mathrm{~g}$ in weight

BCG: Prepared at the National Institute of Health

Strain of Murine Leprosy Bacillus: The leproma of the Kumamoto strain passed through rats was extirpated and suspended in saline warer. The concentrations used were $10^{-2}$ and $10^{-4}$.

80 rats were devided into four groups of each 20 rats. BGG was injected, then after 3 months $0.5 \mathrm{cc}$ of each murine leprosy bacillus suspension was, as an challenging manner. inoculated subcutaneously.

The size and the weight of the leproma were the standards of the judgement. Distribution of bacillus and pathological changes in the lymph nodes and visceral organs were helpful to the judgement.

Results: As presented in Tables 1 and 2, Figures 1 and 2 and Plate, the onset was inhibited most strongly in the group received $10 \mathrm{mg}$ BCG intraperitoneally. The group which had received subcutaneous inoculation of $10^{-4}$ suspension showed pretty strong inhibition, while the inoculation of $10^{-2}$ suspension presented no difference from the control group.

From the above results, it was revealed that the preceding BCG injection prevented the onset of murine leprosy, and BGG was more effective when injected intraperitoneally than subcutaneously. And that the diluted suspension was more adequate than the concentrated.

II. Inhibition of the onset

Experimental method: Rat, BCG and murine bacillus suspension employed in this experiment were the same as those in experiment of prophylaxis. This time, 20 rats inoculated $0.5 \mathrm{cc}$ of $10^{-2}$ suspension and other $200.5 \mathrm{cc}$ of $10^{-4}$ suspension. The half number of each group received subcutaneous injection of $10 \mathrm{mg}$ of BCG on the next day and observed. The standards of the judgement were the same as those described in the previous experiment.

Results: As in Tables 3 and 4, and figures 3 and 4,10 rats inoculated $10^{-2}$ bacillary suspension presented no remarkable difference between the treated and the non-treated groups, while those in inoculated $10^{-4}$ suspension BCG injection produced a more intense inhibition. These

* the deceased 
results revealed that $\mathrm{BCG}$ injection inhibited the onset of murine leprosy to some extent.

III. Therapeutic Experiment

20 rats which had already developed, 3 months after subcutaneous inoculation of murine leprosy bacillus, pea-sized or almond-sized leprom at the site were injected subcutaneously. 10 of the above 20 rats then received $10 \mathrm{mg}$ of BCG 10 times in every week. In this treatment, BCG injection produced no noticeable difference between the treated and non-treated groups (Tab. 5). In short, BCG showed no therapeutic effect.

These three series of experiments presented conclusion that BGG injection is a useful method for the prophylaxis and the inhibition of the onset of murine leprosy.

\title{
BCGによる鼠癩否疫の研究
}

\author{
西村真二 故河野通之巟玉 正道 \\ 大阪大学微生物病研究所頛研究部 大阪大学医学部皮筒科泌尿器科教室 \\ 柳沢謙 \\ 国立予防衛生研究所 \\ 野島泰治守屋睦夫高橋竹代 \\ 大島 新之助
}

国立療荃所大島青松園

伊東正保鈴木 正和

国立療養所長撚冢生園

(昭和 31 年 4 月 23 日受稿)

Vaccin による癩の予防は, 瀨菌培養が成功した後に 取上げらるべき課題として，てれまで多くの人々は市ま り関心を示さなかつた。然るにB C G 接種によつてレプ ロミン反応が陽転する事実を Fernandez ${ }^{21}$ によつて見出 されて以来, この研究はにわかに脚光を浴びるに至つ た。即ちレプロミン反忍は, 癩の病型決定に重要な指標 としてその意義を認められているものであるが，一方と の反応の陽性は, 瀨菌に対する生体抵抗力の現われで出 るとの考え方から， B C G 接種による癩予防の問題が大 きく浮び上つて来た。そして南フメリカ珠にブラジルで はこの研究が旺ん行われ，既に同国々立 Leprosy Serviceでは数年前から大規模な野外研究が実施されている 程である。

鼠瀨を対象とした B C G Vaccination の吥究は，こ の問題の解決に幾分で的立つで岕ろらとして $2 \cdot 3 の$ 人達がこれを試みている。Azulay ${ }^{1)}$ は，1952年 B C G のラット接種は, 鼠霣発症をある程度抑制すると予報し たのち引続いて行つた多数の実験成績も, 確実にこのこ
とを証明したと報告している。然るにてれよりさき

Muir \& Henderson ${ }^{6}$ ) は 1927一28年彼等の鼠瀬に関する 綜説に扎いて B C G 接種が鼠寶の予防に効果なきととを 述べ，1954年 Hadler \& Zitti ${ }^{5}$ ) 的彼等の実験成績站に病 理組織学的見地加ら， B C G による鼠癩発症の抑制を 否定している。1955年著者等のちち西村, 河野等 ${ }^{8)}$ は,

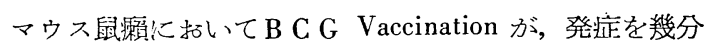
抑制したと発表し，川口王) は弱毒結核菌（B C G）よ りも強毒株 (H $37 \mathrm{RV}$ ) 感染マウスに扔いて, より強く 鼠瀨発症を抑制したと述べている。

われわれは，鼠癩実験の成果をそのまま䅋へ援用し得 るや否やは別としても, 現在 B C Gによる哃感染予防の 実験的な研究手段としては，乙れを鼠癩に求めるほかな いので，ここに本実験を企てた次第でもる。

\section{実験材料涉に方法}

この実験を感染予防（Vaccination したラットを鼠瀨 菌で攻檕する), 発应阻止（鼠瀨菌を接種した後から 
Vaccinaiton t行う), 治療（鼠瀨菌接種 3 力月後瀨腫の 発症せるものを対象汇治療)，の 3 つに大別し，

ラットは，静闾県産，雑系， $70 \mathrm{~g} \pm 10 \mathrm{~g}$ ，文を用い，

BCGは，国立予防衛生研究所の液状ワクチン（製造 後3.日）を背部皮下及び腹腔内へ接種した。

鼠癩菌は，熊本株ラット継代後 3 カ月の新鮮な瀨腫を 摘出既砕，生理的食塩水にて $10^{-2}$ 乳剤とし，乙れを 4 層のガーゼにて㴔過，更に $10^{-4}$ 稀跀液を作り，接種は 各菌夜とも $0.5 \mathrm{cc}$ ずつ総て下腹部皮下へ行つた。接種菌 液中の菌数は次の通りであつた。

$10^{-2}$ 液 $0.5 \mathrm{cc}$ に 1840 万個， $10^{-4}$ 液 $0.5 \mathrm{cc}$ に 18.4 万 個。

実験方法は，次の様に行つた。

1）感染予防（ラット80匹）

1955年 1 月 30 日，B C G を下記の如くラットへ注射し た後， 3 カ月後に鼠瀨菌を以つて攻撃し， 5 カ月間発症 経過を镜察後解剖した。

\begin{tabular}{|c|c|c|c|c|}
\hline \multirow{2}{*}{ ラット } & \multicolumn{2}{|c|}{ B C G } & 攻 揧 菌 & \multirow{2}{*}{ 観繁期間 } \\
\hline & 接種部 $\mathrm{mg}$ & 免疫期間 & 稀勫液 cc & \\
\hline 10 & 皮下 10.0 & 3 カ月 & $10^{-2} \quad 0.5$ & 5 カ月 \\
\hline 10 & " " & " & $10^{-4} "$ & " \\
\hline 10 & ") 1.0 & " & $10^{-2} \mathrm{II}$ & " \\
\hline 10 & " " & " & $10^{-4}$ & " \\
\hline 10 & 腹腔10.0 & " & $10^{-2}$ & " \\
\hline 10 & " " & " & $10^{-4}$ & " \\
\hline 10 & $\begin{array}{l}\text { 無処置 } \\
\text { 凉 }\end{array}$ & & $10^{-2}$ & " \\
\hline 10 & " & & $10^{-4} "$ & $"$ \\
\hline
\end{tabular}

2) 発症阻止 (ラット40匹)

1955年 1 月29日，鼠顆菌を下記の樣にラットへ接種し その翌日 B C G を注射， 5 カ月間発症程度を旛祭した後 に解剖した。

\begin{tabular}{|c|c|c|c|c|}
\hline ラット & $\begin{array}{l}\text { 攻撃囷 } \\
\text { 稀䣋液 }\end{array}$ & & $\begin{array}{l}\text { B C G } \\
\text { 注射 } \mathrm{mg}\end{array}$ & 観繁殺 \\
\hline 10 & $10^{-2} \quad 0.5$ & 翌日 & 腹腔 10 & 5 力月 \\
\hline 10 & $10^{-4} "$ & " & " & " \\
\hline 10 & $10^{-2} "$ & & 無処置対照 & " \\
\hline 10 & $10^{-4} "$ & & $"$ & " \\
\hline
\end{tabular}

3）治療（ラット20匹）

1955年 1 月29日，ラット10匹にに鼠瀬菌 $10^{3}$ 稀唒液 0.5 cc を下腹部皮下へ接種し， 3 力月後局所に㴡腫の癹生し

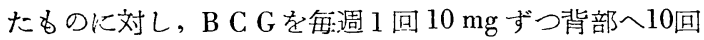
注射した。対照群10匹は無処置のますとした。
成績判定法は，鼠瀨菌接種部に打ける癩腫の抎がりに 重点を扎いて，其の経過を1 カ月每に観察し， 5 カ月栙 にこれを剖検して，その重量，リンパ節及び臟器に㧊け る菌分布, 潂化臟器の病変を参考にして, 下記の方法て 判定を行つた。

櫴腫判定標準

皮下接種局所に生じた Leproma をゲージによつて拉 がりを測定したのちメスを以て丁寧に摘出，脂肪組織， 血液成分などを除いて評量し拡がりは下記の祭準によ二 て判定評価した。

\begin{tabular}{|c|c|c|}
\hline 瀨腫の抎がり & 触 診 & 記 号 \\
\hline $1 \sim 30 \mathrm{~m} \cdot \mathrm{m}^{2}$ & 痕跡～半米粒大 & $\perp$ \\
\hline $31 \sim 70$ & 米粒大 & + \\
\hline $71 \sim 150$ & 小豆大 & H \\
\hline $151 \sim 300$ & 小指頭大 & H \\
\hline
\end{tabular}

菌分布度の判定標準

リンパ節及び瀻器割面をスタンプし，チールネルせン 染色を施した祭本の鏡検成績を，下記の標準に従い判定 評価した。

$\begin{array}{ccc}\text { 全視野の含菌細胞数 } & \text { 記 号 } & \text { 指 数 } \\ \text { 孤立菌のみ小数 } & \perp & 1 \\ 1 \sim 10 & + & 2 \\ 11 \sim 50 & H & 3 \\ 51 \sim 100 & H & 4 \\ 101 \text { 以上 } & \infty & 5\end{array}$

\section{実 験 成 績}

\section{1 感染予防成績}

a) 瀨腫の発生経過（Table 1. Fig 1. 参照）

無処置対照群: $10^{-2}$ 菌乳蝺接種組では 30 日後から既 に浸潤文は小結節を生じ，日の経つにつれて顆腫増大， 150 日では平均指数 2.0 を示した。同じく $10^{-4}$ 菌乳剂接 種組では60日後から浸潤，結節を生じ，其の後比較的急 速に增大して 150 日では平均指数 1.6 であつた。

B C G $1 \mathrm{mg}$ 皮下注射群：10-2 菌乳剤による攻慗組で は，一見して発症がやや扣くれたよらであつたが，逐次 增大し 150 日では平均指数 1.9 を示し, 対照群のそれと 殆んど差が見られなかつた。10-2 菌乳剂攻揧組では60 日目から浸潤を認めたが，その程度は対照群よりも軽 く，150日では平均指数 1.06 でかなり抑制された。

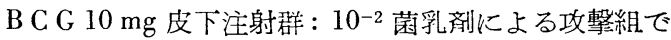
は，対照化比し発症がやや扎くれたが，其の後速かに增 大 150 日では平均指数 2.3 を示し，対照群よりも却つて 大であつた。1 $10^{-4}$ 菌乳羭攻撃組では，対照に比して発 
苂がかなり強く抑制され 150 日目の平均指数は 0.68 であ つた。

B C G $10 \mathrm{mg}$ 腹腔注射群：10-2 菌乳郕攻撃組では, 対 㙰比し発症時期もはるかに打くれ，60日目に約半数に るいて漸く浸潤を触れたが，其の後との瀨腫は増大を見
ず，かつ発症動物数も增加せず 150 日に颃いてて却つて 浸潤の消褪したものがあつて，平均指数 0.28 之云う甚たて 低いものでむつた。10-4 菌乳蝺攻撃組では，乙れ亦強 く抑制され 150 日目の瀨腫平均指数 0.17 と云ら全実験中 の最低值を示した。

Table 1. The Progress of the Growth of Leproma in

Prophylaxis Experiment

\begin{tabular}{|c|c|c|c|c|c|c|c|c|c|c|c|c|c|}
\hline \multirow[b]{2}{*}{ BCG } & \multirow[b]{2}{*}{ Days } & \multicolumn{6}{|c|}{$\begin{array}{c}10^{-2} \text { suspension } \\
0.5 \mathrm{cc}\end{array}$} & \multicolumn{6}{|c|}{$\begin{array}{c}10^{-4} \text { suspension } \\
0.5 \mathrm{cc}\end{array}$} \\
\hline & & No. & 30 & 60 & 90 & 120 & 150 & No. & 30 & 60 & 90 & 120 & 150 \\
\hline \multirow{8}{*}{ 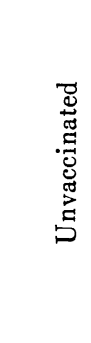 } & \multirow{8}{*}{ 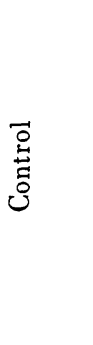 } & 101 & $\perp$ & + & & $H$ & H & 111 & - & $\perp$ & + & + & \\
\hline & & 102 & + & & + & + & + & 112 & - & $\perp$ & $H$ & +1 & + \\
\hline & & 103 & + & & H & $H$ & $H^{+}$ & 113 & - & $\perp$ & + & + & + \\
\hline & & 104 & $\perp$ & + & + & + & + & 114 & - & $H$ & + & + & + \\
\hline & & 105 & + & H & $H$ & $\mathrm{H}^{1}$ & $\mathrm{HH}^{+}$ & 115 & - & $\perp$ & + & + & $\mathrm{Ht}$ \\
\hline & & 106 & + & + & + & H & + & 116 & - & $\perp$ & + & + & + \\
\hline & & 107 & + & $H$ & + & $H$ & Ht & 117 & - & + & + & +1 & H \\
\hline & & & & & & & & 118 & - & $\perp$ & - & $\perp$ & + \\
\hline \multirow{8}{*}{ 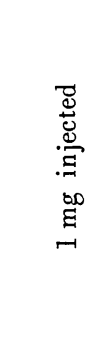 } & \multirow{8}{*}{ 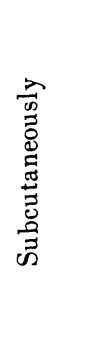 } & 81 & - & $\perp$ & + & H & $\mathrm{HH}$ & 91 & - & + & $\perp$ & + & $H$ \\
\hline & & 82 & - & + & + & $H$ & HH & 92 & - & $\perp$ & $\perp$ & $\perp$ & + \\
\hline & & 83 & + & + & + & $H^{H}$ & H & 93 & - & $\perp$ & $\perp$ & $\perp$ & + \\
\hline & & 84 & $\perp$ & + & + & + & - & 94 & - & $\perp$ & $\perp$ & + & + \\
\hline & & 85 & $\perp$ & + & + & + & + & 95 & - & $\perp$ & $\perp$ & + & + \\
\hline & & 86 & $\perp$ & $\perp$ & + & + & + & 96 & - & $\perp$ & $\perp$ & + & + \\
\hline & & 87 & - & + & + & + & $H$ & 97 & - & $\perp$ & $\perp$ & $\perp$ & $\perp$ \\
\hline & & 88 & $\perp$ & + & + & + & + & 98 & - & $\perp$ & - & $\perp$ & + \\
\hline \multirow{8}{*}{ 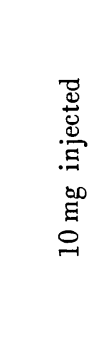 } & \multirow{8}{*}{ 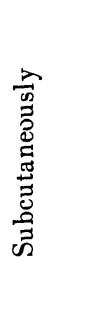 } & 61 & $\perp$ & + & + & $H$ & $\mathrm{Ht}$ & 71 & - & - & - & - & - \\
\hline & & 62 & - & + & + & + & + & 72 & - & $\perp$ & $\perp$ & $\perp$ & + \\
\hline & & 63 & $\perp$ & + & $\mu$ & + & + & 73 & - & $\perp$ & $\perp$ & $\perp$ & + \\
\hline & & 64 & + & $H$ & $H$ & $H^{H}$ & $\mathrm{HH}$ & 74 & - & $\perp$ & $\perp$ & $\perp$ & + \\
\hline & & 65 & - & + & + & $H^{1}$ & HH & 75 & - & $\perp$ & $\perp$ & $\perp$ & + \\
\hline & & 66 & + & + & + & + & + & 76 & - & $\perp$ & - & $\perp$ & $\perp$ \\
\hline & & & & & & & & 77 & - & $\perp$ & $\perp$ & $\perp$ & $\perp$ \\
\hline & & & & & & & & 78 & - & - & - & - & $\perp$ \\
\hline \multirow{9}{*}{ 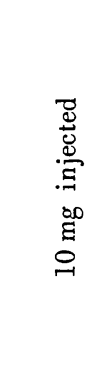 } & \multirow{9}{*}{ 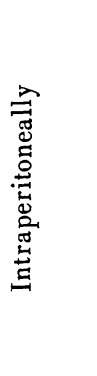 } & 121 & - & + & $\perp$ & + & $\perp$ & 131 & - & $\perp$ & $\perp$ & $\perp$ & $\perp$ \\
\hline & & 122 & - & - & - & - & - & 132 & - & - & - & - & - \\
\hline & & 123 & - & $\perp$ & $\perp$ & + & H & 133 & - & - & - & - & - \\
\hline & & 124 & - & - & - & + & - & 134 & - & $\perp$ & $\perp$ & $\perp$ & $\perp$ \\
\hline & & 125 & - & $\perp$ & - & - & - & 135 & - & - & - & - & - \\
\hline & & 126 & - & $\perp$ & $\perp$ & $\perp$ & - & 136 & - & $\perp$ & $\perp$ & + & $\perp$ \\
\hline & & 127 & - & - & - & - & - & 137 & - & - & - & - & - \\
\hline & & 128 & - & + & $\perp$ & $\perp$ & $\perp$ & 138 & - & $\perp$ & $\perp$ & $\perp$ & - \\
\hline & & 129 & $\perp$ & $\perp$ & $\perp$ & $\perp$ & - & 139 & - & - & $\perp$ & .1 & - \\
\hline
\end{tabular}


Table 2 The weight of Leproma and Distribution of Bacilli in Prophylaxis Experiment

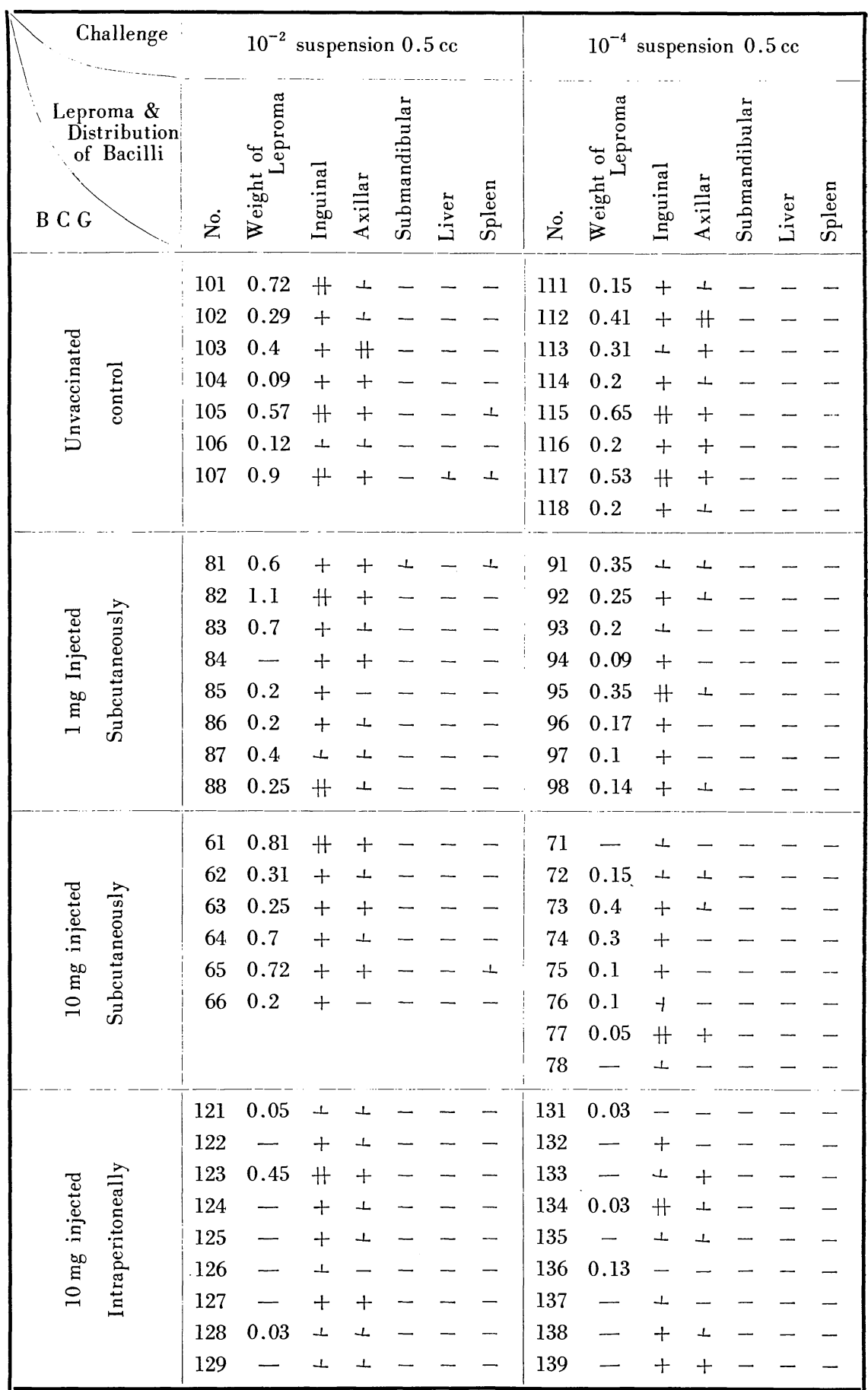


Fig 1 は, 各群別の発症経過の平均指数をとストグラ ムに表わしたもので，とれによつて B C G 各群を比較す ると，皮下注射法よりも腹腔内法が有効に作用やると とが一目瞭然でめつて， B C G 注射量では $1 \mathrm{mg}$ と 10 $\mathrm{mg}$ との間に著しい差を見ない。又攻撃菌量の側から見 ると, 濃厚菌液 $\left(10^{-2}\right)$ よりも, 稀薄菌液 $\left(10^{-4}\right)$ によ る攻撃組に扔いて，B C G の抑制が一層明確に観察でき た。

b) 瀨腫重量と菌分布 (Table 2, Fig 2, Plate 参照)

無処置対照群: $10^{-2}$ 菌乳隹攻撃組では, 瀨腫平均重量 $0.42 \mathrm{~g}$, 菌は全例の鼠蹊腺, 腋窩腺に Globi 状をなして +〜程度認めたが，顎下腺にはこれを見ず，臓器では 旰 1 例, 脾 2 例に Globi にまで発展していない土程度 の菌を見出した。1 $10^{-4}$ 攻撃組では嶰腫平均 $0.33 \mathrm{~g}$, 全例 の鼠蹊腺, 腋窝腺によ〜州程度の菌を認めたが, 顎下 湶，肝，熷には菌を見出さなかつた。

B. C. G. I mg 皮下注射群: 10-2 菌乳剩攻撃組では癩
腫平均重量 $0.43 \mathrm{~g}$, 菌は全例の鼠蹊腺によ〜 H程度見ら れたが，腋曧腺では 6 例，顎下腺は 1 例にのみ発見，臓 器では脾の 1 例に少数を認めた。1 $10^{-4}$ 攻撃組では瀨腫重 量 $0.21 \mathrm{~g}$ ，菌は鼠蹊腺の全例に証明できたが，腋窩腺は 4例のみ少数に発見，他は見出さなかつた。

B C G $10 \mathrm{mg}$ 皮下注射群：10-4 菌乳㓩攻馨組では瀨 腫重量 $0.14 \mathrm{~g}$, 菌分布は鼠蹊腺の全例, 股窩腺の 3 例に とれを認めたが，他は見出せなかつた。

B C G $10 \mathrm{mg}$ 腹腔内注射群：10-2 菌乳剩攻慗組では, 癩腫を摘出し得たもの僅かに 3 例, 他は痕跡或は全くこ れを認めなかつたものでせる。その重量平均 $0.6 \mathrm{~g}$ であ つた。

菌は鼠蹊腺の全例に認めたが，Globi を証したもの 5 例で，他は細胞内に专つても極少数で出つた。腋窩腺も 亦 1 例を除き全部菌を認めたが，その大部分は極く少数 であつた。他の淋巴腺臓器には菌を見出せなかつた。 $10^{-4}$ 攻揧組では癩腫を摘出し得たもの 3 例, 平均して

Table 3 The Progress of the Growth of Leproma in Experiment of Inhibition

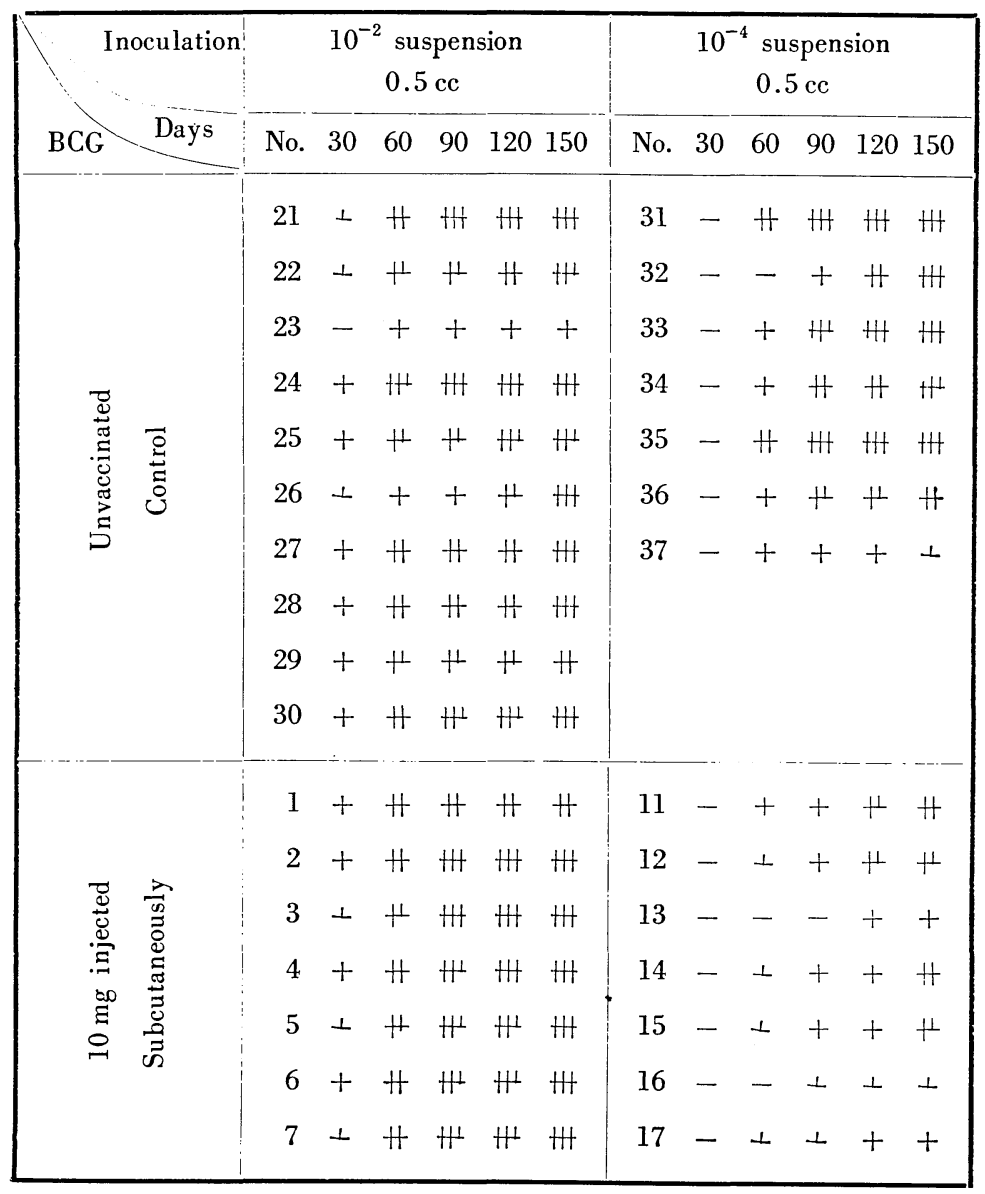


${ }^{0} .01 \mathrm{~g}$ ，菌は鼠蹊腺に証明したもの 7 例，腋祸腺 5 例で 頜喰菌数の少い例が多かつた。

Fig 2 は以上の瀨腫平均重量, 菌分布を各群每に比較 したものでめつて, 重量はさきの発症経過と概和一致し た成績を示し，菌分布では一般に B C G 注射群は対照 群上りも軽く, $1 \mathrm{mg}$ 皮下群と，10 mg 皮下群の間纪は 大差ないが，腹院内注射では皮下注射よりも一層低く対 照群との間比はかなり強い抑制が認められた。

\section{2 発症阻止成績}

a) 瀨腫の発生経過（Table 3 参照）

無処置対照群: $10^{-2}$ 菌乳剤接種組では，30日で 1 例 を除き全部に浸潤又は結節を生じ，日数の経過と共に増
大 150 日では平均指数 2.6 にまで発展した。一方 $10^{-4}$ 接 程組では，30日で発症したものは 1 例も無かつたが，45 〜60日で全部発症，のち急速に增大して150日では平均 指数 2.3 に達した。

B C G $10 \mathrm{mg}$ 皮下注射群: $10^{-2}$ 菌乳剂接種組では 30 日で全例に発症，以後各例とも逐次増大し，150日では 平均指数 2.9 を示し，対照群に比し全く抑制が見られな い。1 $10^{-4}$ 接種組では 30 日で発症したものなく，60日で 漸く 5 例に浸潤を認め, 150 日ではその多くが小結節に 増大, 平均指数 1.4，乙れは対照群に較べてかなり強く 抑制された。

Fig 3 は上記各群の発症経過平均指数を表わしたもの

Table 4. The Weight of Leproma and Distribution of Bacilli in Experiment of Inhibition

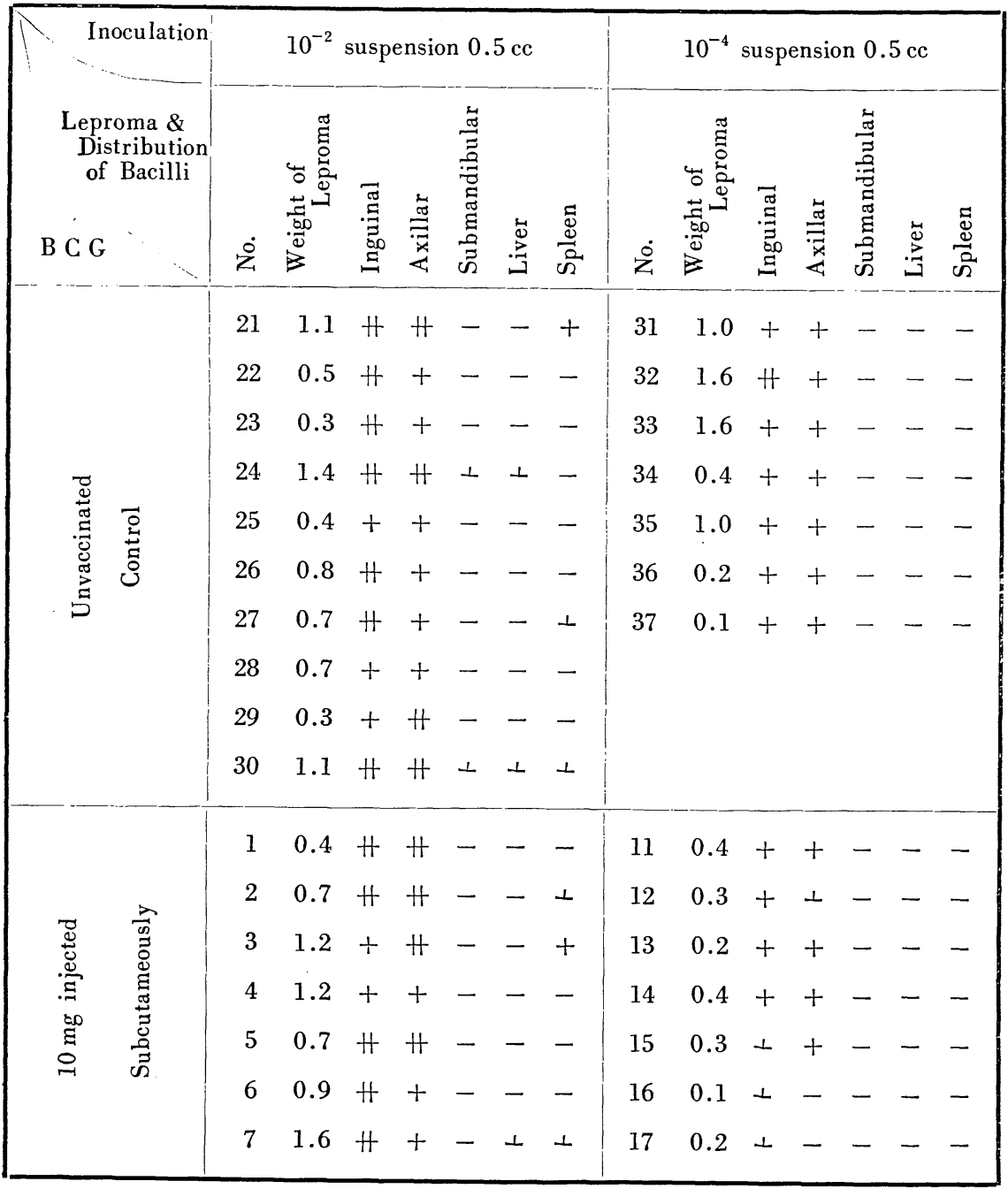


である。

\section{b）瀨腫重量と菌分布 Table 4 参照）}

無処置対照群: $10^{-2}$ 菌乳刜接種組では, 瀨腫重量平均 $0.73 \mathrm{~g}$, 菌は鼠蹊腺, 腋敫腺に Globi を形成して十〜H 程度見られ, 顎下腺は 2 例, 肝 2 例, 脾 3 例にいずれも 少数の菌を認めた。 $10^{-4}$ 接種群では, 瀬腫重量平均 0.48 $\mathrm{g}$, 菌は鼠蹊腺, 腋窩腺に証明したが, 他の淋巴腺及び臟 器には見なかつた。

B C G $10 \mathrm{mg}$ 皮下注射群：10-2 菌液注射群では䙡腫重 量平均 $0.96 \mathrm{~g}$ で, 対照群よりあ却つて大きく, 菌分布 では対照と殆んど同程度に証明したので，抑制的効果は 殆んど見られなかつた。 $10^{-4}$ 接種群では瀨腫重量平均 $0.27 \mathrm{~g}$, 対照群に比しかなり強く抑制され, 菌は大部分
の鼠蹊腺，腋窩腺に証明できたが，その菌数は甚だ少く 対照に比較して顕著ではないが僅かに差が見られた。

Fig 4 は上記各群の瀬腫重量平均涉に菌分布指数を表 わしたものでする。

\section{3 治療成績}

Table 5 に示した如く, 対照群も B C G 治療群も45 日頃より発症, 90日では共に平均指数 1.8 の同值を示し たものでむるが, 以後 B C G を 1 週 1 回 $10 \mathrm{mgずつ} 10$ 回注射したものでは，乙れによる影響は全く見受けられ ず，150日で対照群平均指数 2.7 , 注射群 2.1 でその間に 著しい差を見ず，治療的効果を示したものが 1 例もなか つた。

Table 5. The Progress of the Growth of Leproma in Therapeutic Experiment

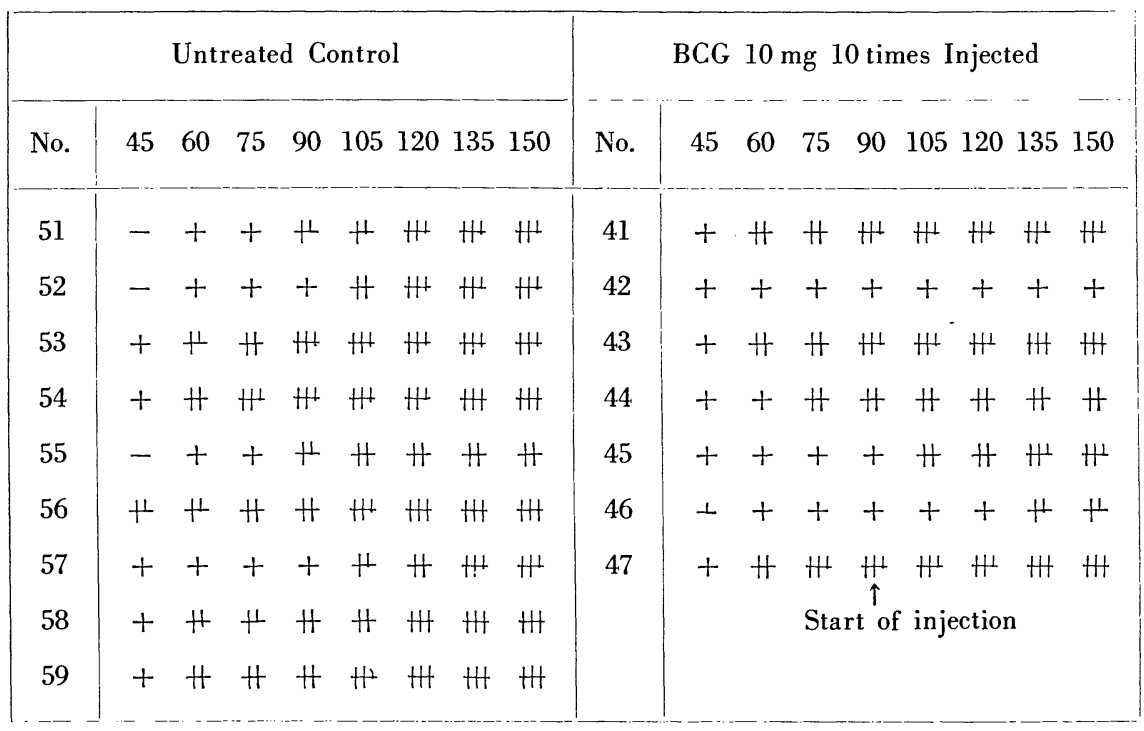

総

括

国立予防衛生研究所にて作られた液状 B C G Vaccin, 鼠瀬菌熊本株（ラット継代 $10^{-2} \sim 10^{-4}$ Suspension)，70 $\sim 80 \mathrm{~g}$ 雑系ラット 140 匹を材料とし, 判定法には皮下接 種局所の獺腫発生経過と, その重量に主眼を置き, 菌分 布を参考として行つた感染予防, 発症阻止, 治療の 3 つ の実験成績は次のよらでもつた。

1）感染予防法として，ラットに B C G を注射して から 3 カ月後に鼠瀨菌を接種するとその発症が抑制され る。この場合 B. C. G. 复腔内注射が最も効果大で，皮 下注射は効果が尠い。又注射量 $1 \mathrm{mg}$ と $10 \mathrm{mg}$ との間に は効果は大差がない。攻撃菌量では, $10^{-2} よ り も 10^{-4}$
菌乳刱を接種した場合に抑制作用を一層明膫に認めた。

2）発酒阻止法として，鼠瀨菌を接種した翌日 B C G を皮下注射すると，発症が幾分抑制される。この場合も 接種菌は乳蝺に打いて効果が明かでめつた。

3）治療的に B C G を用いても効果がなかつた。

\section{討論}

はじめに述べた如く，鼠瀨を対象とした B C G 免度に 関する報告はいまだ五指を屈するに足りない，にも係ら ずその成績は必ずしも一定でない。B C G 免疫の研究が 最も熱心に行われているブラジルに於いても, Azulay ${ }^{1}$ は之を肯定した成績を示し，Hadler 等) はこれに反し た結果を報じている。そしてわれわれが上に述べた成績 
は，その可能性を支持するものである。

この様に成樍のくい違いが生じた最も大きい理由とし
て先つ考えられるととは，実験方法の相違でむる。試み に3者の実験方法を次表について比較するに,

\begin{tabular}{|c|c|c|c|}
\hline 実 験 法 & Hadler \& Zitti5) & Azulay ${ }^{1)}$ & 西村, 柳沢, 野島等 \\
\hline $\begin{array}{l}\mathrm{B} \text { C G 投 } \\
\text { 与法と菌量 }\end{array}$ & $\begin{array}{l}\text { 経口: } 5 \mathrm{mg} 5 \text { 回=25 mg } \\
\text { " } 5 \mathrm{mg} 1 \text { 回 }=5 \mathrm{mg} \\
\text { 筋肉: } 5 \mathrm{mg} 1 \text { 回 }=5 \mathrm{mg} \\
\text { 非予防注射対照群 }\end{array}$ & $\begin{array}{l}\text { 皮下: } 20 \mathrm{mg} 1 \text { 回 } \\
\text { 腹腔: } 20 \mathrm{mg} 1 \text { 回 } \\
\text { 非予防注射対照群 }\end{array}$ & $\begin{array}{l}\text { 皮下: } 1 \mathrm{mg} 1 \text { 回 } \\
\text { " } 10 \mathrm{mg} 1 \text { 回 } \\
\text { 榎腔: } 10 \mathrm{mg} 1 \text { 回 } \\
\text { 非予防注射対照群 }\end{array}$ \\
\hline 動 物 数 & 50 匹 & 77 匹 & 80 匹 \\
\hline 免疫期間 & 90 日 & 115 日 & 90 日 \\
\hline 攻 撃 菌 & 腹腔内へ $0.03 \mathrm{mg} 2$ 回 & $\begin{array}{l}\text { 皮下へ Rich Suspension } \\
0.5 \mathrm{cc}\end{array}$ & 皮下へ $\begin{array}{r}10^{-2} 0.5 \mathrm{cc} \\
10^{-4} 0.5 \mathrm{cc}\end{array}$ \\
\hline 判定 法 & $\begin{array}{l}\text { 内臓病変の程度涉に組 } \\
\text { 織変化 }\end{array}$ & $\begin{array}{l}\text { 解剖による局所病変と } \\
\text { 菌分布 }\end{array}$ & $\begin{array}{l}\text { 局所 Leproma 発生経 } \\
\text { 過と重量涉に菌分布 }\end{array}$ \\
\hline 結 & 対照に比し差なし & $\begin{array}{l}\text { 局所の病変には差あり } \\
\text { 菌分布には大差なし }\end{array}$ & $\begin{array}{l}\text { Leproma の発生に顕 } \\
\text { 著な差あり, 菌分布に } \\
\text { は僅に差あるのみ }\end{array}$ \\
\hline
\end{tabular}

B C G 投与方法, 及び攻撃菌量とその接種部位站に判 定方法に重要な違いが見出される。先ず接種部位である がわれらの成樍にも表われたよらに，B C G 皮下注射よ りも, 腹腔内注射がより効果的であつたととから見て, Hadler 等の用いた経口投与又は筋内内注射法が, 果し て腹腔内注射と同様に有効であるかどか，疑問といわ ざるを得ない。次に攻撃菌量について, Azulay は濃厚 乳哓 (Rich Suspension) を皮下に, Hadler は $0.03 \mathrm{mg}$ を榎腔に注射している(この $0.03 \mathrm{mg}$ は, 交献2)による われ等の計算では $10^{-2}$ 乳郕 $0.3 \sim 0.5 \mathrm{cc}$ に相当した)。

このよらな濃厚乳羭接種では，僅少な抑制力を判定す るととが全難であるととは，既にわれわれが B C G 皮下 接種群に対する $10^{-2}$ と, $10^{-4}$ 乳刜接種成績で知らされた ところである。又 Azulay 及びわれわれは主として皮下 接種法による瀨腫の発生と, 菌分布によつて判定を行つ ているが，Hadler は腹腔接種によつて淢器病変の肉眼 的站に組織学的所見で判定を試みている。とのような㖑 器に打ける肉眼的病変を, 一定の尺度によつて評価する ととは甚价むつかしいととであり，又 B C G 注射群と 非注射群に托ける病像の特徴を組織学的に把えるととも とれまた至難なととと考えられ，寧ろ皮下局所に打ける 瀨腫の発生を, 一定の規準に照して評価するととが, 最 も合理的であると私どもは考える。

Hadler 等が鼠瀨の B C G 免疫を否定する理由は, 単 に彼等がラットについて行つた免疫実験で, 好ましい結
果が得られなかつたといらだけではなく，彼等がそれよ り以前に行つたモルモットとラットへ鼠瀨菌を接種した 場合の比較研究4) など B C G 免度に関する一連の実験成 樍から，モルモットではB C G 注射によつて Lepromin 反応陽転と共に Macrophagen の菌溶解作用を充進する が,ラトではこれがない。即ちラットの Macrophagen の 菌貪喰能は，モルモットのそれよりも強いが，先天的に 溶菌作用を示さず, 叉B C G 注射によつてとの作用を高 めるととが出来ないと云う事実根拠を㧊けるすのであ る。果して鼠瀨免疫力の本態を, Macrophagen のみと 考えてよいであろらか，てれは今後の研究に俟つとして も, われらの実験方法によつて, 局所の Leproma の発 生が明かに抑制された事実は，乙れを免疫現象と云う言 葉を以つて説明して，一向さしつかえないように思う。 即ちわれわれは, Hadler と異つた方法, として Azulay の方法よりも一層小量の鼠瀨菌を以つて攻撃するととに よつて,より明確に抑制作用を認めるととができたので むる。

結論

ラットに B C G を皮下又は腹腔内注射して一定期間 後に鼠瀨菌を以て攻撃した場合, 発症が抑制される。こ の事実によつて，B C G による鼠瀬免度は可能である と結論したい。

この実験は要生園光田健輔園長の助言によつて野島, 柳沢, 西村等が計 
画をたて，次のような分担によつて実施された。 B C G 製造とラットえ の注射は柳沢が, 鼠廮菌接種と成續の判定は西村等が担当し, 動物の飼育 管理其の他実験の一切は大島青松園野島園長のもとにおいて各医官の協力 によつて行われたものである。文献314)51 Hadler の報告は, 阪大志水助教 授の邦訳に負うものである。

終りにこの研究に対し 援助を与えられた藤㮯協会に対し謝意を表する。

\section{文献}

1) Azulay, R. D.: The Protective Role of B. C. G. in Murine Leprosy, Internat. J. Leprosy 22 61, (1954)

2) Fernandez, J. M. M. Estudio comparativo de la reaccion de Mitsuda con la reacciones tuberculinicas. (Comparative study of the Mitsuda and tuberculin reactions) Rev. Argentina Dermatosifl. 23 425-453, (1939). Abs.-Internat. J. Leprosy 8 133, (1940)

3) Hadler, W. A., Zitti, L. M.: Estudo da sensibilidade tuberculinica em cobaios normais inoculados experimentalmente com M. leprae, M. lepraemurium e M. tuberculosis, Revista Brasileira de Leprologia
21 341, (1953)

4) Hadler, W. A.: Comportamento do cobaio e do rato, normais, injetado com "lepromina" por via intradermica, Revista Brasileira de Leprologia Vol. 21165 (1953)

5) Hadler, W. A., Zitti, L. M. : Efeito da vacinação pelo BCG sōbre a evolução da lepra murina : observaçao em ratos inoculados, por vir peritoneal, com pequena dose de "mycobacteryam lepra murium," Revista Brasileira de Leprologia 22 124, (1954)

6）川口陽一郎：瀨と結核の免度学的関連性について 第一編 結核感染の鼠瀨発症に及ぼす影響 レプラ 2464 (昭和30年)

7) Muir, E. and J. M. Hendersson: Rat leprosy Indian J. M. Research 15807 (1927-28)

8）西村，河野，坚玉：瀨と鼠瀨の免没に関する研究 (2 報) レプラ 24427 (昭和30年) 学会抄録 
Fig. 1. The Average Value of the Growth of Leproma in Each Group of Prophylaxis Experiment

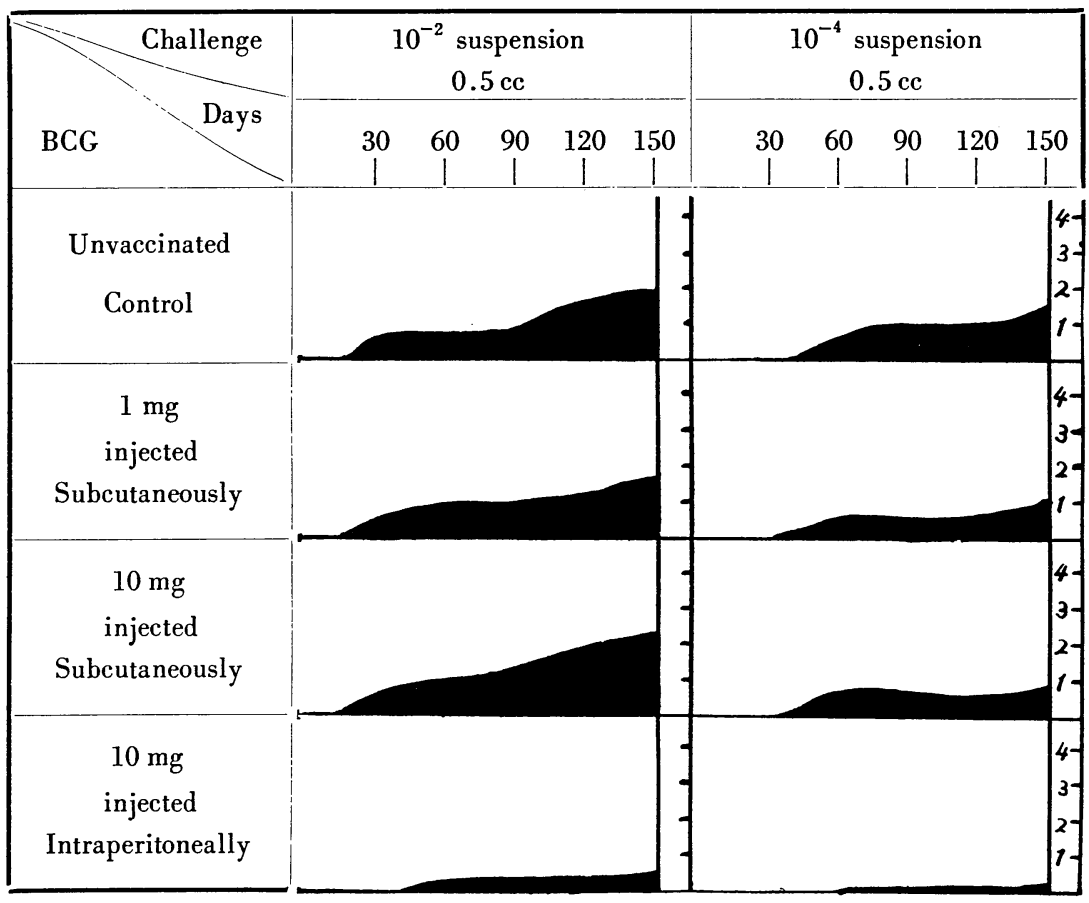

IFig. 2. The Average Value of the Weight of Leproma and Distribution in Each Group of Prophylaxis Experiment

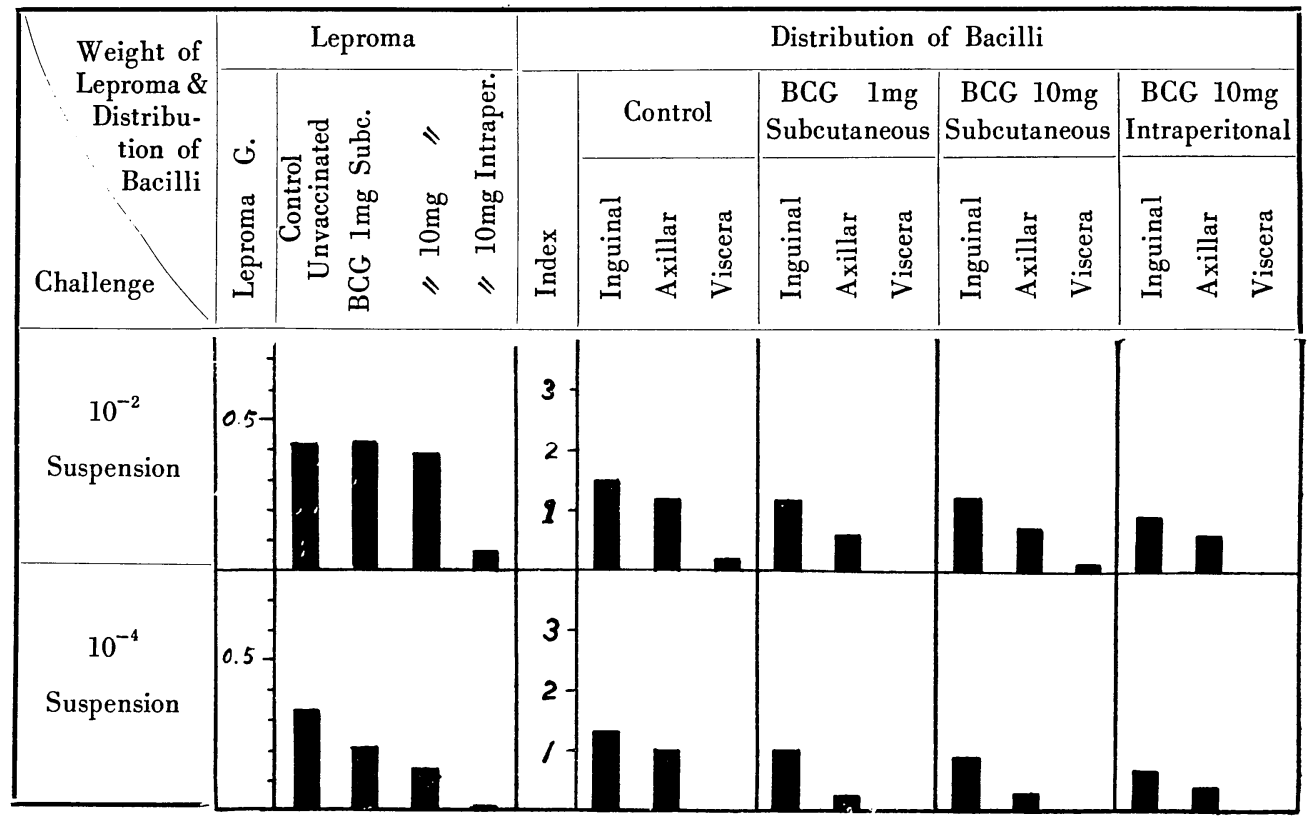


Fig. 3. The Average Value of the Growth of Leproma in Each Group of Inhibition Experiment

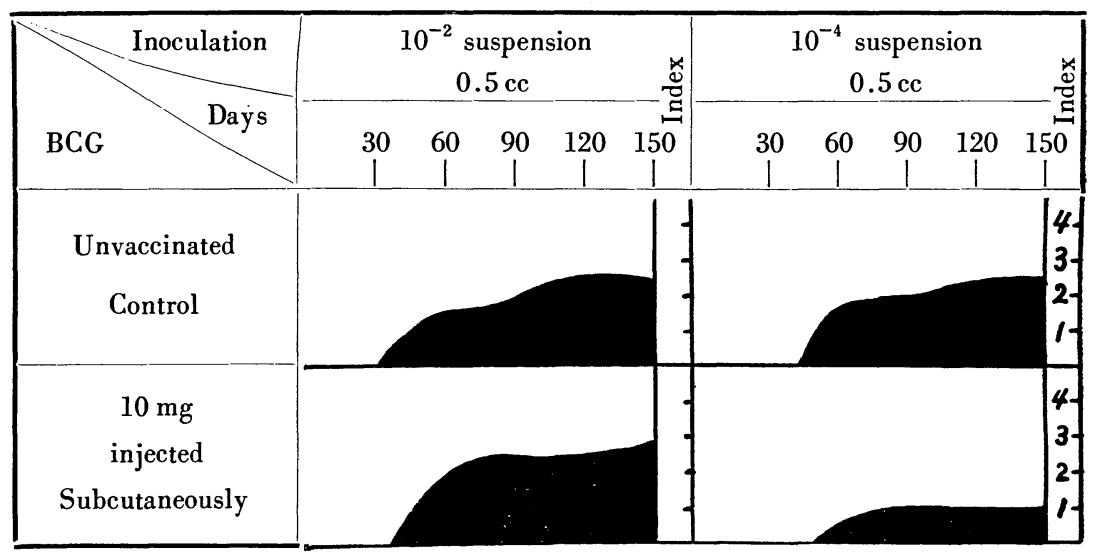

Fig. 4. The Average Value of the Weight of Leproma and Bacillus Distribution in Experiment of Inhibition

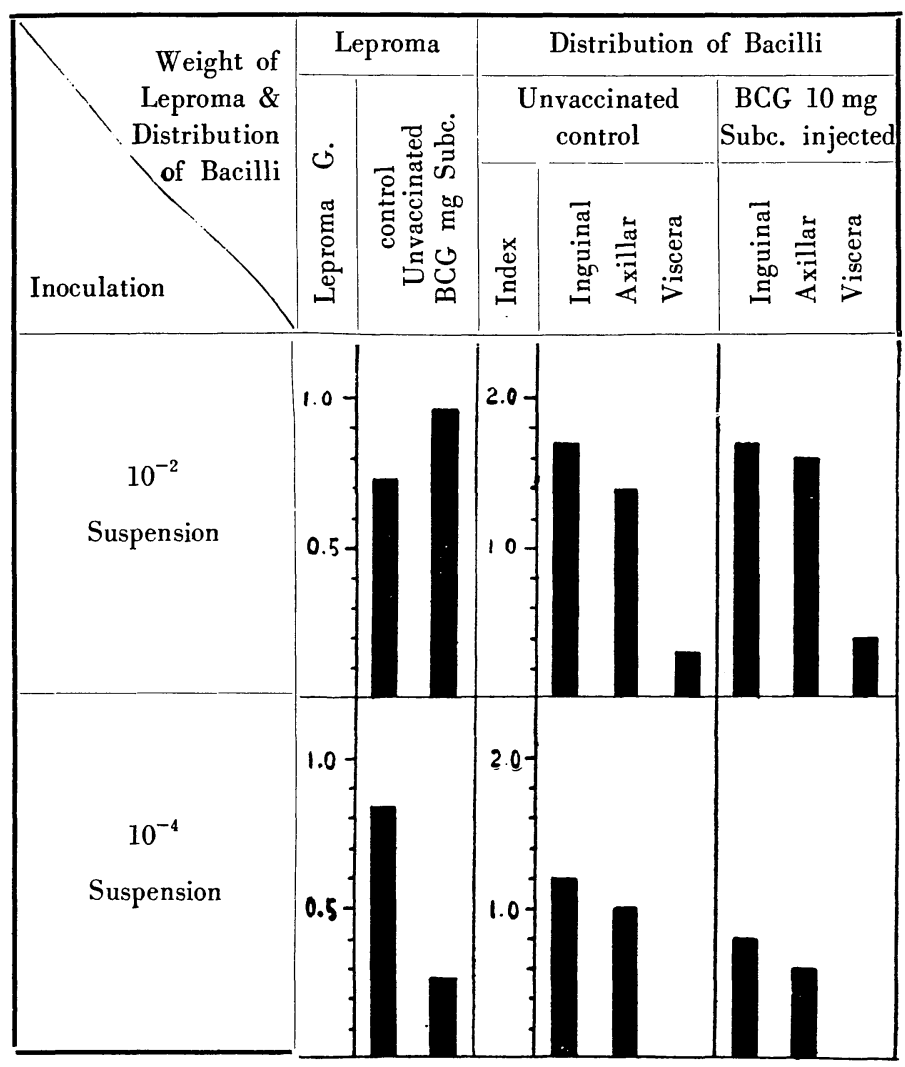




\section{PLATE I}

The Leproma Developed in Prophylaxis Experiment

(Challenge Bacilli 10-2 Suspension)

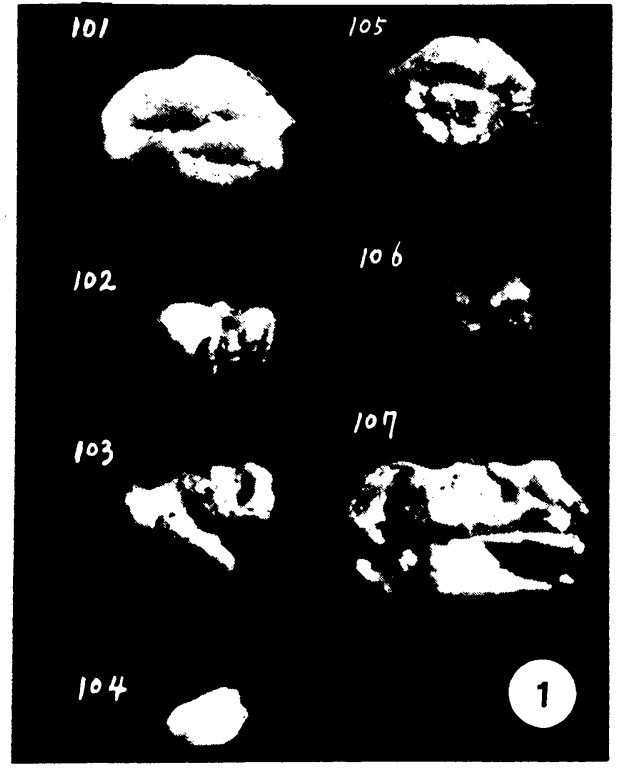

1. Unvaccinated Control

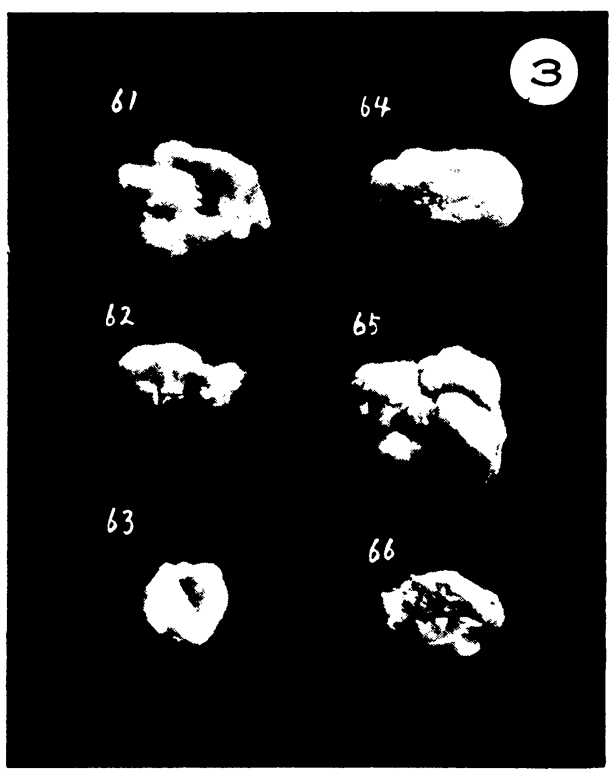

3. BCG $10 \mathrm{mg}$ Subcutaneously Injected

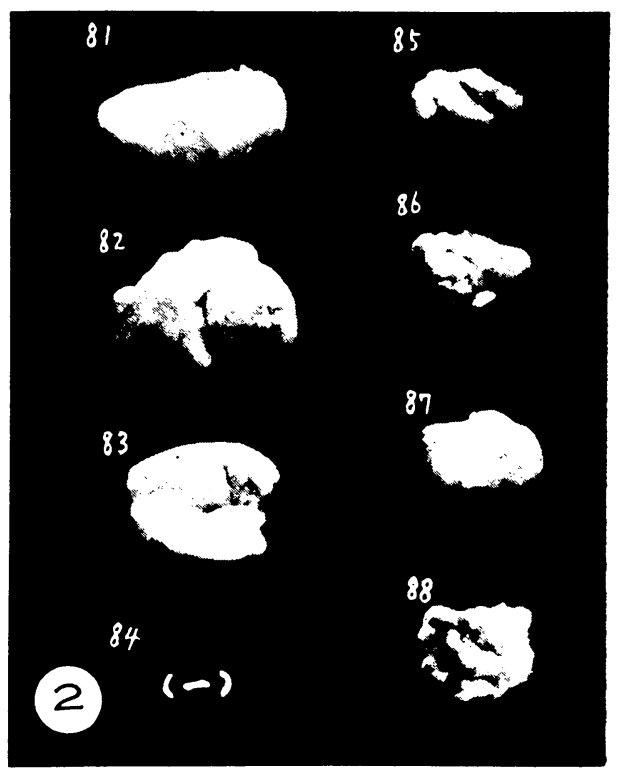

2. BCG 1mg Subcutaneously Injected

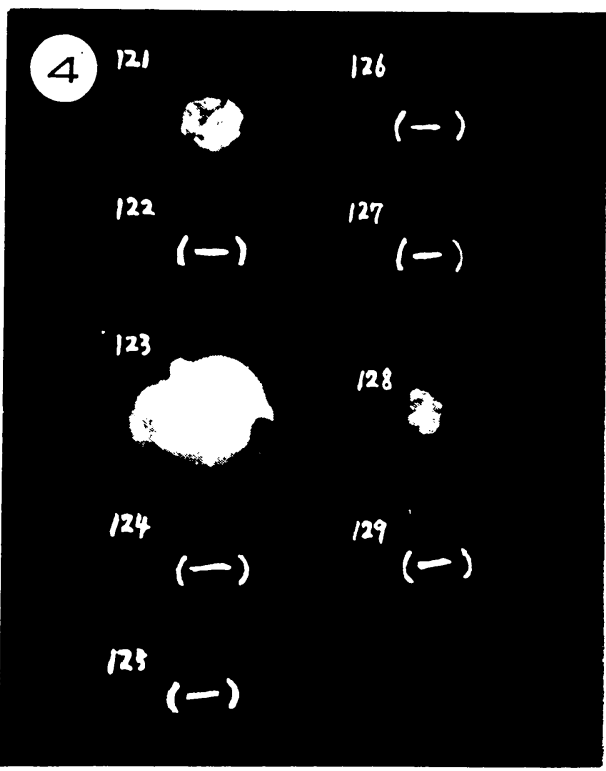

4. BCG 10mg Intraperitoneally Injected 


\section{PLATE II}

The Leproma Developed in Prophylaxis Experiment

(Challenge Bacilli $10^{-4}$ Suspension)

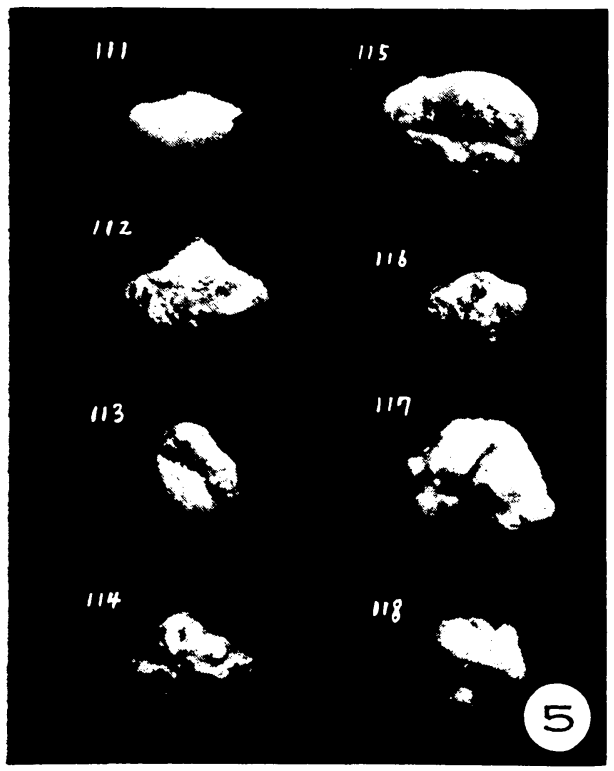

5. Unvaccinated Control

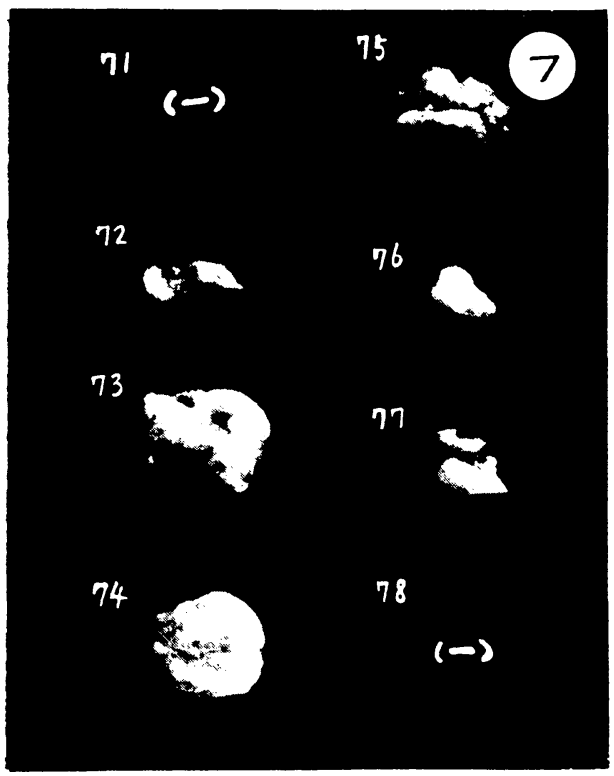

7. BCG $10 \mathrm{mg}$ Subcutaneously Injected

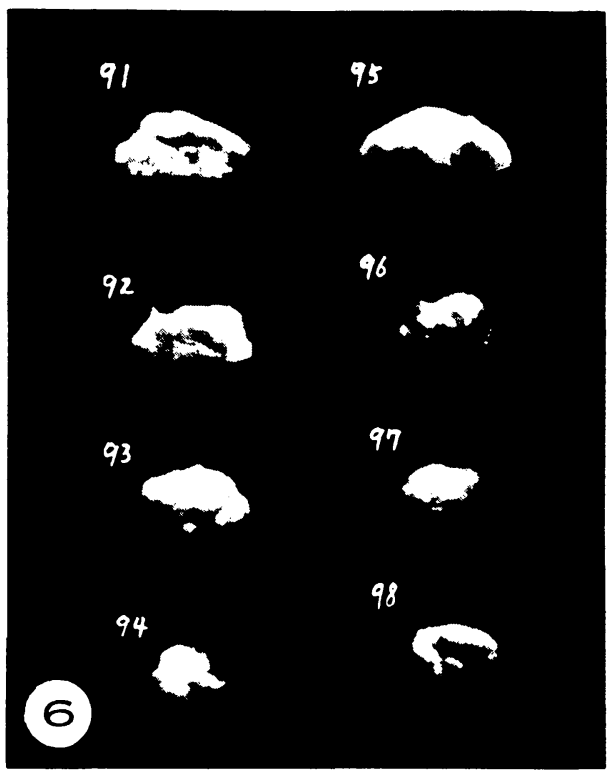

6. BCG $1 \mathrm{mg}$ Subcutaneously Injected

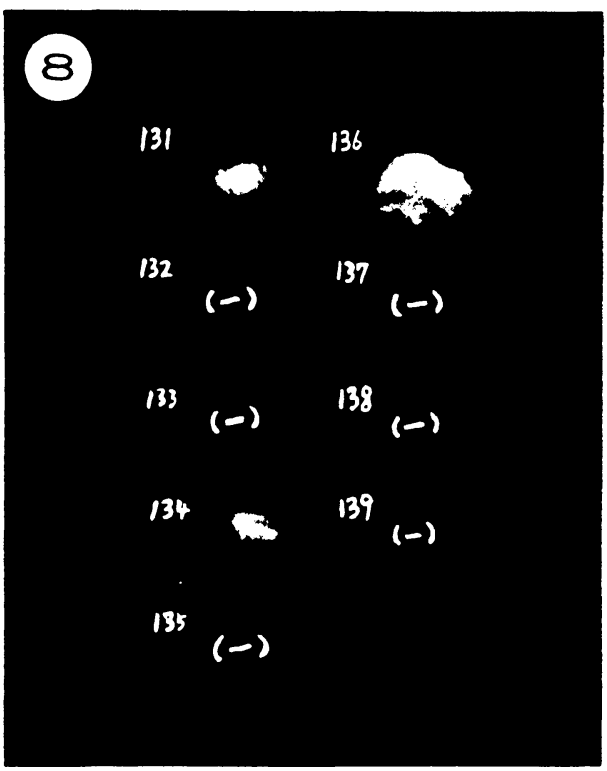

8. BCG $10 \mathrm{mg}$ Intraperitoneally Injected 